\title{
Increased Catabolic Rate of Low Density Lipoproteins in Humans with Cholesteryl Ester Transfer Protein Deficiency
}

\author{
Katsunori Ikewaki, Masato Nishiwaki, * Takuya Sakamoto, ${ }^{\ddagger}$ Toshitsugu Ishikawa, ${ }^{\star}$ Thomas Fairwell, Loren A. Zech, \\ Makoto Nagano, ${ }^{\ddagger}$ Haruo Nakamura, ${ }^{*}$ H. Bryan Brewer Jr., and Daniel J. Rader \\ Molecular Disease Branch, National Heart, Lung and Blood Institute, National Institutes of Health, Bethesda, MD 20892;* The First \\ Department of Internal Medicine, National Defense Medical College, Saitama, Japan; and ${ }^{\ddagger}$ Department of Internal Medicine, Aoto \\ Hospital, Jikei University School of Medicine, Tokyo, Japan
}

\begin{abstract}
The cholesteryl ester transfer protein (CETP) transfers lipids among lipoprotein particles and plays a central role in lipoprotein metabolism. Humans with genetic deficiency of CETP have both elevated HDL cholesterol and apolipoprotein A-I concentrations as well as decreased LDL cholesterol and apolipoprotein B levels. The.present study was undertaken to elucidate the metabolic basis for the decreased LDL cholesterol and apo B levels in CETP deficiency. We conducted a series of in vivo apo B kinetic studies in two unrelated homozygotes with CETP deficiency and in control subjects. A primed constant infusion of stable isotopically labeled phenylalanine was administered to the two CETP deficient subjects and control subjects and apo $B$ kinetic parameters in VLDL, intermediate density lipoproteins, and LDL were obtained by using a multicompartmental model. The fractional catabolic rates (FCR) of LDL apo B were significantly increased in the CETP-deficient subjects $(0.56$ and 0.75/d) compared with the controls (mean FCR of 0.39/ d). Furthermore, the production rates of apo B in VLDL and intermediate density lipoprotein were decreased by $55 \%$ and $81 \%$, respectively, in CETP deficiency compared with the controls. In conclusion, CETP-deficient subjects were demonstrated to have substantially increased catabolic rates of LDL apo $B$ as the primary metabolic basis for the low plasma levels of LDL apo B. This result indicates that the LDL receptor pathway may be up-regulated in CETP deficiency. (J. Clin. Invest. 1995. 96:1573-1581.) Key words: cholesteryl ester transfer protein • kinetics • stable isotopes - low density lipoproteins • apoliprotein B
\end{abstract}

\section{Introduction}

Plasma concentrations of LDL are correlated with the risk of coronary heart disease (1). Apo B-100 is the major protein associated with LDL. LDL are derived from VLDL, which are secreted by the liver. VLDL triglycerides undergo hydrolysis by the action of lipoprotein lipase and are converted to smaller

\footnotetext{
Address correspondence to Katsunori Ikewaki, First Department of Internal Medicine, National Defense Medical College, 3-2 Namiki, Tokorozawa, Saitama, Japan, 359. Daniel Rader's present address is University of Pennsylvania Medical Center, 422 Curie Blvd., BRB-1, Room 409, Philadelphia, PA, 19104. Phone:215-898-4011; FAX:215-573-8606.

Received for publication 7 March 1994 and accepted in revised form 1 June 1995.
}

The Journal of Clinical Investigation, Inc.

Volume 96, September 1995, 1573-1581
VLDL and finally to intermediate density lipoproteins (IDL). ${ }^{1}$ Further lipolysis mediated by hepatic lipase converts IDL to LDL. During this lipolytic cascade, lipoprotein particles can be directly removed by the liver. VLDL and IDL have been proposed to removed primarily via the remnant receptor and the LDL receptor with apo $E$ as the ligand, while $L D L$ is catabolized via the LDL receptor. Thus, LDL cholesterol levels are regulated by several factors: rate of secretion of the precursor lipoprotein (VLDL), partitioning of VLDL pathway between direct removal and conversion to LDL, the affinity of LDL for the LDL receptor, and the hepatic LDL receptor activity (2).

Cholesteryl ester transfer protein (CETP) is a plasma glycoprotein which catalyzes the transfer of cholesteryl esters and triglycerides among lipoproteins $(3,4)$. There is a net transfer of cholesteryl ester from HDL to apo B-containing lipoproteins which are eventually converted to LDL. The transferred cholesteryl esters present in LDL are taken up by the LDL receptor in liver and peripheral tissues. Complete CETP deficiency in humans (5-8) has been proposed to be associated with longevity (5). Homozygotes for CETP deficiency have markedly elevated HDL-C and plasma apo A-I levels as well as decreased LDL-C and plasma apo B levels $(6,9,10)$. In addition, LDL in CETP deficiency differ from normal LDL in being cholesteryl ester poor and triglyceride rich as well as more polydisperse in size (11-13). These findings imply a role of CETP in the metabolism of both HDL as well as apo B-containing lipoproteins. In a previous apo A-I kinetic study, we established that markedly delayed apo A-I catabolism accounts for the elevated plasma apo A-I levels in CETP deficiency (14). However, the exact mechanism by which CETP deficiency results in low levels of apo B has not been established.

The present study was undertaken to determine the metabolic effect of CETP deficiency on apo B metabolism in vivo. The first series of studies was designed to address whether isolated CETP-deficient LDL are rapidly catabolized in control subjects, addressing the question of whether the abnormal lipid composition of CETP-deficient LDL alters its catabolism. In the second series of studies, we used an endogenous stable isotope labeling method to directly investigate apo B metabolism in CETP-deficient subjects.

\section{Methods}

Study subjects. Two unrelated homozygotes for CETP deficiency and nine control subjects were investigated. The CETP-deficient subjects

1. Abbreviations used in this paper: CETP, cholesteryl ester transfer protein; FCR, fractional catabolic rate; IDL, intermediate density lipoprotein; $\mathrm{PR}$, production rate. 


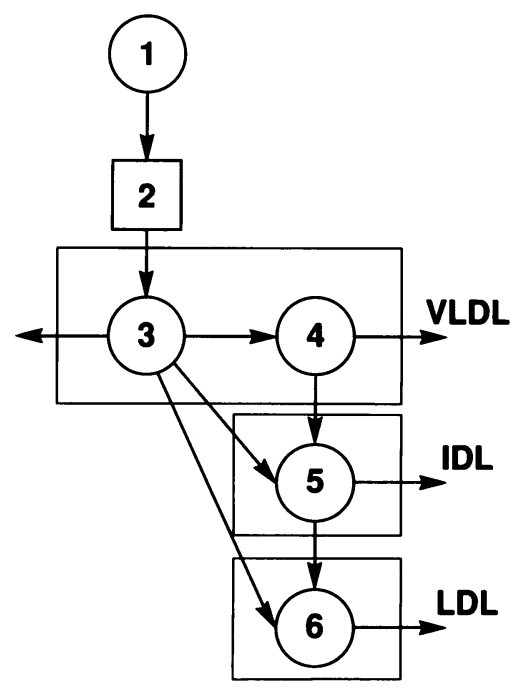

Figure 1. The compartmental model used to fit apo B tracer/tracee data for the CETP-deficient subjects and control subjects. Compartment 1 represents the plasma amino acid (phenylalanine) pool and was used as a forcing function. Compartment 2 represents the delay time for the synthesis and secretion of apo B. Compartments 3 and 4 are VLDL subfraction pools and compartments 5 and 6 are the IDL and LDL pools.

were both homozygous for the $\mathrm{G}$ to A point mutation of the intron 14 splice site as previously reported (14). All study subjects had normal fasting plasma glucose levels and normal thyroid, hepatic, and renal function. The study protocol was approved by the Internal Review Boards of Jikei University School of Medicine (Tokyo, Japan) and the National Heart, Lung and Blood Institute (Bethesda, MD). Informed consent was given by each of the participants.

Study 1: kinetic study of CETP-deficient LDL in control subjects. LDL (density $=1.019-1.063$ grams $/ \mathrm{ml}$ ) were isolated by sequential ultracentrifugation from (15) the two CETP-deficient homozygotes and from three control subjects. After extensive dialysis against PBS, the lipoproteins were applied to an anti-apo A-I immunoaffinify column. Unbound fractions were collected and reapplied to the anti-apo A-I column to remove the buoyant HDL particles present in this density range in CETP deficient plasma $(12,14,16)$. Purity of the LDL in the unbound fraction was confirmed by agarose as well as native gradient polyacrylamide gel electrophoresis before labeling. LDL from CETPdeficient subjects and control subjects were dialyzed against a 1-M glycine ( $\mathrm{pH} \mathrm{10}$ ) buffer and labeled with ${ }^{125} \mathrm{I}$ and ${ }^{131} \mathrm{I}$, respectively, as previously reported (17). Labeled LDL were extensively dialyzed at $4^{\circ} \mathrm{C}$ against PBS containing $0.01 \%$ EDTA overnight. The samples were sterile-filtered through a $0.22-\mu \mathrm{m}$ filter (Millipore Corp., Bedford, MA) and tested for pyrogens and sterility before injection.

$3 \mathrm{~d}$ before injection, study subjects were placed on an isoweight diet. $1 \mathrm{~d}$ before the study, the subjects were given potassium iodide (900 mg) which was continued throughout the study period. CETPdeficient ${ }^{125} \mathrm{I}-\mathrm{LDL}$ and autologous control ${ }^{131} \mathrm{I}$-LDL were injected into three control subjects after a 12 -h fast. Blood samples were obtained
10 min after the injection and then $1,3,6,12$, and $24 \mathrm{~h}$ and at $2,3,4$, $5,7,9,11,14 \mathrm{~d}$. Blood was drawn into tubes containing EDTA at a final concentration of $0.1 \%$ and plasma was immediately separated by low speed centrifugation. Radioactivity in a 4-ml plasma aliquot was quantitated in a Packard Cobra gamma counter (Packard Instrument Co., Downers Grove, IL). Plasma radioactivity curves were constructed by dividing the plasma radioactivity by the 10 -min plasma counts and were fit to two exponentials using SAAM 31 (18). Residence times were determined by the area under the curves and fractional catabolic rates (FCR) were the reciprocal of the residence times.

Study 2: apo B kinetic studies in CETP-deficient subjects. After a 12$\mathrm{h}$ fast, ${ }^{13} \mathrm{C}_{6}$-phenylalanine $\left(99 \%{ }^{13} \mathrm{C}_{6}\right.$; Cambridge Isotope Laboratories, Woburn, MA) was administered to the two homozygous CETP-deficient subjects and six control subjects as a priming bolus of $600 \mu \mathrm{g} / \mathrm{kg}$, immediately followed by a constant infusion of $12 \mu \mathrm{g} / \mathrm{kg}$ per min for up to $12-16 \mathrm{~h}$. Blood samples $(20 \mathrm{ml})$ were obtained from the opposite arm at $10 \mathrm{~min}, 1,2,3,4,5,6$, and every $2 \mathrm{~h}$ until the end of infusion. During the infusion, meals were served in equal small portions every 2 h. Plasma was immediately separated by centrifugation at $2,300 \mathrm{rpm}$ for $30 \mathrm{~min}$ at $4^{\circ} \mathrm{C}$. VLDL, IDL, LDL were isolated by sequential ultracentrifugation from $5 \mathrm{ml}$ of plasma and processed for the analysis by a gas chromatography-mass spectrometry as previously described (14). Briefly, lipoproteins were dialyzed against $10 \mathrm{mM}$ ammonium bicarbonate, lyophilized, and delipidated. Apo B-100 was isolated by preparative gradient $\mathrm{NaDodSO}_{4}$-PAGE (5-15\%). Apo B-100 bands were cut from gels, dried overnight $\left(90^{\circ} \mathrm{C}\right)$, and subjected to hydrolysis in $6 \mathrm{~N} \mathrm{HCl}$ (Ultrapure grade; J. T. Baker, Inc., Phillipsburg, $\mathrm{NJ}$ ) at $110^{\circ} \mathrm{C}$ for 24 $h$. The protein hydrolysates were lyophilized in a Speed-Vac evaporator (Savant Instruments, Inc., Farmingdale, NY). Plasma-free amino acids and protein hydrolysates were purified by cation exchange chromatography (AG-50W-X8; Bio-Rad Laboratories, Richmond, CA). Recovered amino acids were derivatized to the $N$-heptafluorobutyryl isobutyl esters, dissolved in ethyl acetate, and analyzed by a gas chromatography-mass spectrometry on a Finnigan MAT 4500 (Finnigan MAT, San Jose, CA) in the chemical ionization mode, using isobutane as the reagent gas. Selective ion monitoring at $418 \mathrm{~m} / \mathrm{z}$ for unlabeled phenylalanine and $424 \mathrm{~m} / \mathrm{z}$ for ${ }^{13} \mathrm{C}_{6}$-phenylalanine was used to determine the isotope ratio. Each sample was analyzed at least three times. Acquired data were converted to tracer/tracee ratios using the method of Cobelli et al. (19).

A multicompartmental model was used to analyze the tracer/tracee data as shown in Fig. 1. $\mathrm{C}(1)$ is the plasma phenylalanine pool and used as the forcing function and described using QL function (18). $\mathrm{C}(2)$ is a delay compartment for lipoproteins assembly in the liver and described as DT(2). C(3) and C(4) are used to represent pools for VLDL subfractions which account for the delipidation chain. $\mathrm{C}(5)$ and $\mathrm{C}(6)$ represent pools in IDL and LDL. L $(I, J)$ is a rate constant from $\mathrm{C}(\mathrm{J})$ to $\mathrm{C}(\mathrm{I})$, which is equal to the rate constant of apo B. We assumed that steady state conditions were maintained throughout the study period. Under these conditions, the fractional synthetic rate is equal to the fractional catabolic rate (FCR). The FCR of VLDL apo B was calcu-

Table I. Characterization of Study Subjects

\begin{tabular}{|c|c|c|c|c|c|c|c|c|c|}
\hline Subjects & Sex & Age & Weight & BMI & $\mathrm{TC}$ & TG & HDL-C & Apo A-I & Apo B \\
\hline & & $\mathrm{yr}$ & $\mathrm{kg}$ & $\mathrm{kg} / \mathrm{m}^{2}$ & & & $m g / d l$ & & \\
\hline \multicolumn{10}{|l|}{ CETP deficiency } \\
\hline 1 & $\mathbf{M}$ & 42 & 83.0 & 26.0 & 251 & 98 & 177 & 210 & 61 \\
\hline 2 & $\mathbf{F}$ & 67 & 42.0 & 18.7 & 282 & 79 & 170 & 216 & 60 \\
\hline \multicolumn{10}{|c|}{ Control subjects $(n=9)$} \\
\hline Mean & & 21 & 65.8 & 23.2 & 180 & 88 & 47 & 120 & 111 \\
\hline SD & & 1.6 & 8.4 & 3.6 & 22 & 38 & 9 & 18 & 11 \\
\hline
\end{tabular}

BMI, body mass index; M, male; F, female. 
Table II. Chemical Composition of LDL in CETP Deficiency

\begin{tabular}{|c|c|c|c|c|c|}
\hline Subjects & Protein & Triglyceride & Phospholipid & Free cholesterol & Cholesteryl ester \\
\hline & \multicolumn{5}{|c|}{ percentage of total mass } \\
\hline \multicolumn{6}{|l|}{ CETP deficiency } \\
\hline 1 & 22.7 & 12.3 & 23.7 & 12.4 & 29.0 \\
\hline 2 & 10.1 & 15.0 & 27.7 & 14.8 & 32.4 \\
\hline \multicolumn{6}{|c|}{ Control subjects $(n=4)$} \\
\hline Mean & 22.9 & 5.9 & 20.1 & 9.3 & 41.9 \\
\hline SD & 3.5 & 1.5 & 1.0 & 0.5 & 1.8 \\
\hline
\end{tabular}

LDL was isolated by using an anti-apo A-I immunoaffinity column from the lipoproteins ( $\mathrm{d}=1.019-1.063 \mathrm{grams} / \mathrm{ml})$.

lated using weighted average of the turnover of the two VLDL pools, as previously reported (20). The formula for VLDL apo B FCR was the following:

VLDL apoB FCR

$=\frac{M(3) \times(L(0,3)+/ L(5,3)+L(6,3))+M(4) \times(L(0,4)+L(5,4))}{M(3)+M(4)}$

where $M(I)$ represents phenylalanine mass in compartment $I$.

The FCR of apo B in IDL and LDL was equal to $(L(0,5)+L(6,5))$ and $L(0,6)$ respectively. Similar models to this have been previously reported by other investigators $(20-22)$. Apo B concentration ( $\mathrm{mg} / \mathrm{dl}$ ) was converted to mass of phenylalanine, $M(I)$, using the relative content of phenylalanine of $6 \%$ based on the reported amino acid composition of apo B-100 (23-25) and plasma volume which was assumed as $4 \%$ of body weight. Due to the uncertainty related to low concentration of apo B in VLDL and IDL, we fixed the calculated value to the measured value for LDL apo B and left VLDL and IDL masses adjustable. The measured VLDL and IDL apo B masses were added to the analysis as weighted data. The data were analyzed to determine the kinetic parameters using the SAAM $31(18)$. The production rates $(\mathrm{PR}, \mathrm{mg} / \mathrm{kg}$ per d) were calculated from the following formula:

$\mathrm{PR}=($ plasma apolipoprotein concentration $) \times($ volume of distribution of the apolipoprotein) $\times$ FCR

The volume of distribution of the apolipoprotein was assumed to be $4 \%$ of the body weight.

Analytical methods. Total cholesterol and triglyceride levels were determined by automated enzymatic techniques on an Abbott VPSS analyzer (Abbott Laboratories, North Chicago, IL). HDL cholesterol was measured by dextran sulfate precipitation (26). Apo B concentra-

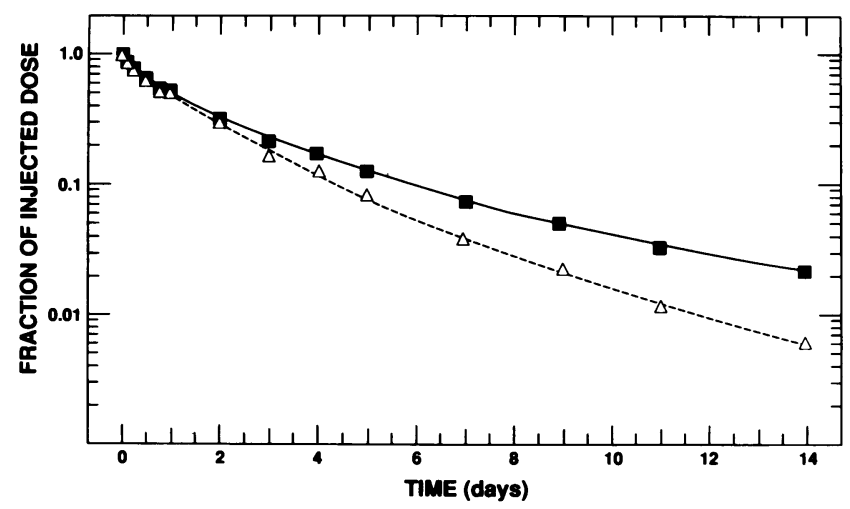

Figure 2. Metabolism of ${ }^{125} \mathrm{I}$-CETP-deficient LDL (filled squares with solid line) and ${ }^{13} \mathrm{I}$-autologous LDL (open triangles with dotted line) in a representative control subject. tion was measured by competitive enzyme-linked immunoassay (27). Lipids and protein content of LDL were determined by enzymatic calorimetric method (Wako chemicals USA, Inc. Richmond, VA) and bicinchroninic acid protein assay (Pierce, Rockford, IL), respectively.

\section{Results}

Characterization of the study subjects. The clinical characteristics and lipid values of the subjects with CETP deficiency are shown in Table I. Values are the mean of five fasting determinations made during the study. Plasma lipid and apolipoprotein concentrations remained in steady state throughout the study period. The nine control subjects had normal fasting lipid and apolipoprotein levels. In the CETP-deficient subjects, plasma apo B levels were $46 \%$ lower than in controls $(P<0.05)$.

Study 1: kinetic study of CETP-deficient LDL in control subjects. Table II provides the composition of LDL isolated from the CETP-deficient and control subjects which was labeled and injected into control subjects. CETP-deficient LDL had less cholesteryl ester and increased triglyceride content compared with control LDL. In addition, we confirmed several discrete subpopulations in CETP-deficient LDL by nondenaturing gradient $(2-16 \%)$ polyacrylamide gel electrophoresis as previously reported $(8,12)$. SDS-polyacrylamide gel electrophoresis of the radiolabeled LDL established that the majority ( $>95 \%$ ) of radioactivity was associated with apo B-100. Plasma decay curves of ${ }^{125} \mathrm{I}$-CETP-deficient LDL and ${ }^{131} \mathrm{I}$-autologous LDL in

Table III. Fractional Catabolic Rates of CETP-deficient LDL and Autologous LDL in Control Subjects

\begin{tabular}{|c|c|c|}
\hline \multirow[b]{2}{*}{ Control subjects } & \multicolumn{2}{|c|}{ Fractional catabolic rates } \\
\hline & CETP-deficient LDL* & Autologous LDL \\
\hline & \multicolumn{2}{|c|}{$d$} \\
\hline 1 & $0.36 \pm 0.004$ & $0.41 \pm 0.004$ \\
\hline 2 & $0.47 \pm 0.006$ & $0.82 \pm 0.011$ \\
\hline 3 & $0.43 \pm 0.016$ & $0.57 \pm 0.009$ \\
\hline Mean & 0.41 & 0.60 \\
\hline SD & 0.05 & 0.17 \\
\hline
\end{tabular}

* CETP-deficient LDL isolated from the CETP-deficient subject 1 was injected into control subject 1 and that from CETP-deficient subject 2 was injected into control subject 2 and 3 . Values are given as best estimates \pm SD. 

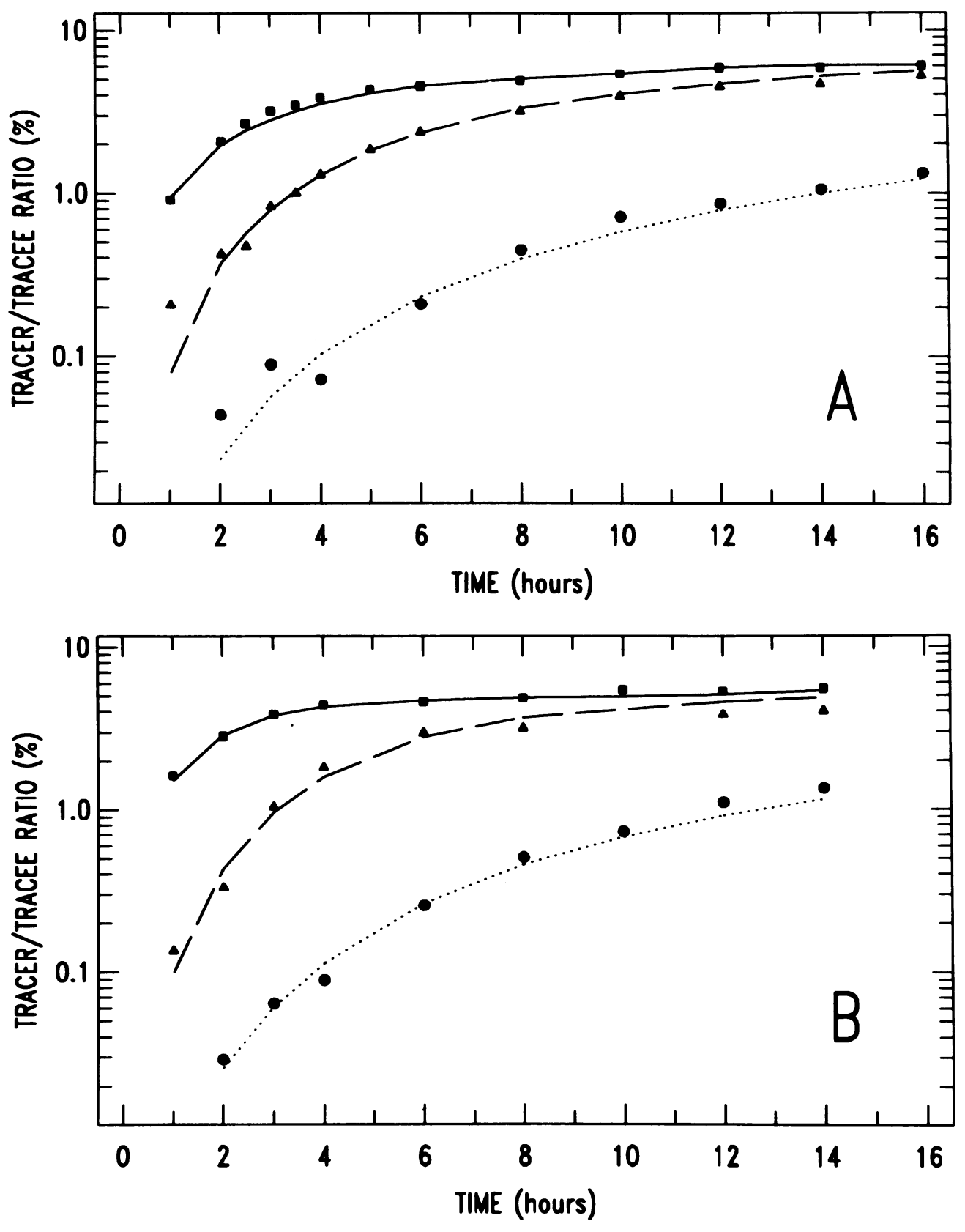

Figure 3. Tracer/tracee ratio curves for VLDL apo B (squares with solid lines), IDL apo B (triangles with dotted lines), and LDL apo B (circles with dashed lines) in the CETP deficient subject $1(A)$, CETP deficient subject $2(B)$, and representative control subject $1(C)$. All the data were fitted by the multicompartmental model described in Fig. 1 using SAAM 31.

a representative control subject (subject 3) are shown in Fig. 2 and the kinetic parameters of CETP-deficient and autologous LDL in all three control subjects are provided in Table III. The mean FCR of CETP-deficient LDL was $0.41 \pm 0.05 / \mathrm{d}$, which was $30 \%$ slower than that of autologous control LDL of 0.60 $\pm 0.17 / \mathrm{d}(P=0.09$ by paired $t$ test $)$. Based on these results, it is unlikely that the altered composition of LDL in CETP deficiency causes rapid catabolism accounting for the decreased LDL apo B levels in these subjects. In contrast, the abnormal CETP-deficient LDL is more slowly catabolized in normal subjects compared with normal LDL.

Study 2: apo B kinetic studies in CETP-deficient subjects. To elucidate the metabolic basis of the decreased LDL apo B levels in CETP deficiency, we performed endogenous stable isotope labeling of apo B in two CETP-deficient subjects. Under a primed constant infusion of labeled phenylalanine, steady state plasma tracer/tracee ratios were $6.8 \%$ for CETP-deficient subject 1 and $9.8 \%$ for subject 2 , and $5.7 \pm 0.4$ (mean \pm SD) for six control subjects. The tracer/tracee ratio curves for VLDL, IDL, and LDL apo $B$ in the two CETP deficient subjects ( $A$ and $B)$ and control subject $1(C)$ are shown in Fig. 3. In the control subjects, as shown in Fig. $3 C$, the apo B tracer/tracee ratios rapidly increased and reached plateau level within 6 to 8 $h$ in VLDL and by the end of the infusion in IDL. The rate of increase of the IDL apo B tracer/tracee ratios in the CETPdeficient subjects was delayed compared with the control subjects. Furthermore, unlike in the control subjects, the IDL apo $B$ tracer/tracee ratios were substantially lower than those of VLDL apo $B$ at the end of the infusion. In contrast, the LDL apo $\mathrm{B}$ tracer/tracee curves in the CETP-deficient subjects were higher relative to the VLDL and IDL curves compared with the control subjects. 


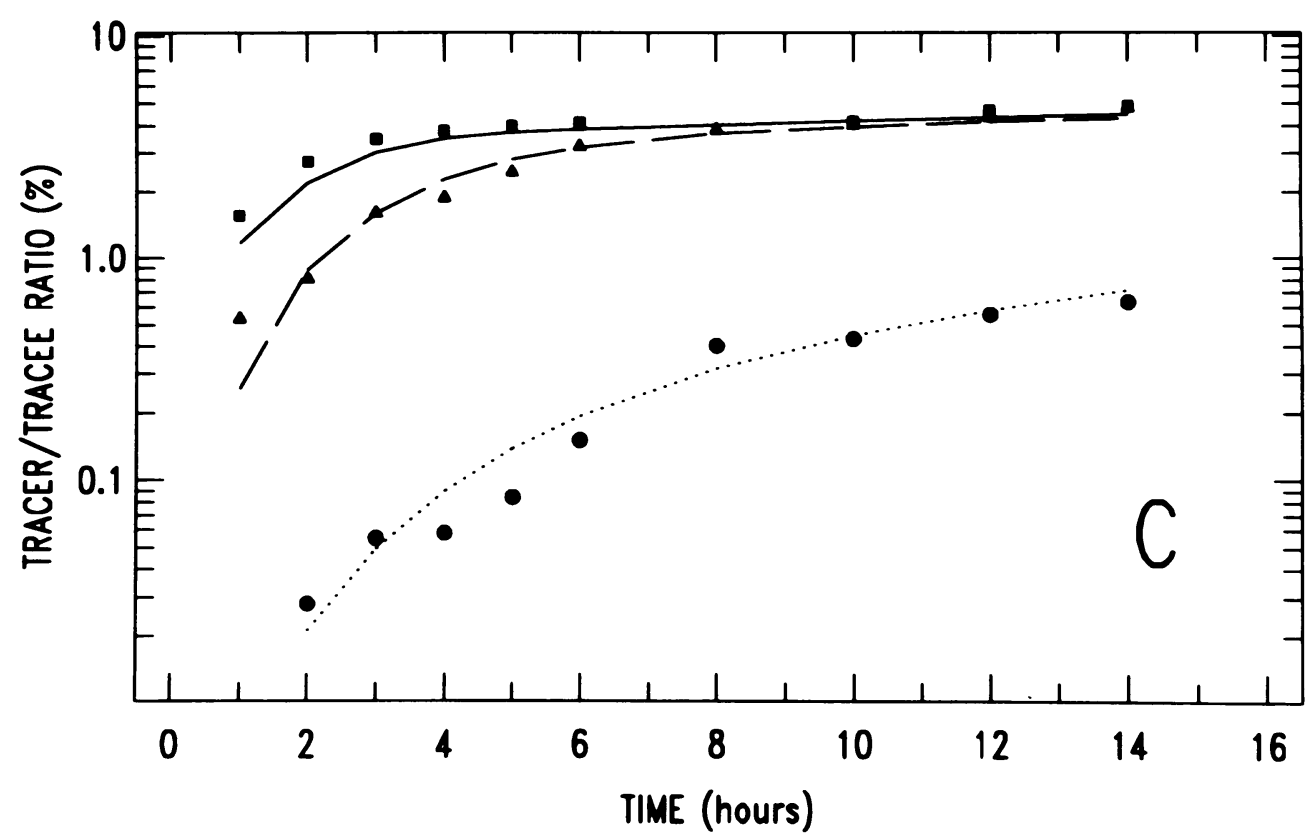

Figure 3 (Continued)

Table IV provides a list of rate constants $(\mathrm{L}(\mathrm{I}, \mathrm{J}))$ and delays (DT(2)) in all study subjects. Although not statistically significant, direct removal from the large VLDL compartment $(\mathrm{L}(0,3))$ was increased by $124 \%$ in the CETP-deficient subjects. Direct removal from the small VLDL compartment was not different between CETP deficient subjects and controls. The rate of conversion from large VLDL to IDL apo B was decreased by $85 \%$ in CETP deficiency, but conversion from small VLDL to IDL apo B was similar between CETP-deficient subjects and controls. Direct conversion of large VLDL to LDL was decreased by $37 \%$ in CETP deficiency, but this was not statistically significant. Direct removal from the IDL compartment was undetectable in CETP deficiency. However, rates of conversion from IDL to LDL in CETP deficiency were not different from those in control subjects. Finally, the rate of removal from LDL was significantly increased by $69 \%$ in CETP deficiency.

The apo B kinetic parameters are summarized in Table V. In the CETP-deficient subjects, VLDL apo B FCRs and production rates were decreased by 41 and 55\% compared with controls. However, the differences were not statistically significant $(P$ $=0.32$ for both FCR and PR). Both the FCRs and PRs of IDL apo B were significantly decreased by 57 and $81 \%$, respectively, in CETP deficiency $(P<0.05)$. Finally, the FCRs of LDL apo B were found to be significantly increased by $69 \%(P<0.05)$ in the CETP-deficient subjects. The LDL apo $B$ production rates were not different in CETP deficiency compared with controls. These results establish that increased catabolism of LDL apo B is the major metabolic basis for the decreased LDL apo B levels in CETP deficiency.

The metabolic channeling of apo B in CETP deficiency is summarized in Table VI. In normal subjects, 34\% of VLDL apo B was directly removed, $52 \%$ was converted to IDL, and $33 \%$ was eventually converted to LDL. In the CETP-deficient subjects, the direct removal of VLDL was slightly increased and the conversion from VLDL to IDL was slightly decreased, whereas the conversion to LDL was increased by $81 \%$. None of these differences, however, were statistically significant. In the controls, most LDL production (87\%) was via the VLDLIDL-LDL cascade, with only $13 \%$ through a shunt pathway (VLDL directly to LDL). In CETP deficiency, however, 26\% of LDL was synthesized through the shunt pathway, a twofold increase compared with controls. Although this increase failed to reach statistical significance $(P=0.18)$, this observation may help to explain the formation of polydisperse LDL in CETP deficiency.

\section{Discussion}

CETP plays an important role in the exchange of lipids among plasma lipoproteins (28). Humans with CETP deficiency have elevated levels of HDL cholesterol and apo A-I $(5,6,8)$. Several investigators have also reported decreased LDL-C and plasma apo B levels in homozygous CETP-deficient subjects $(6,10)$. The hypothesis that CETP has a direct effect on LDL cholesterol and apo B levels was supported by the findings of increased LDL-C and apo B levels in transgenic mice overexpressing CETP (29) and the correlation of CETP mass with LDL-C and apo B levels in cynomolgus monkeys fed a high cholesterol diet (30). To elucidate the metabolic basis for the decreased plasma apo B levels in CETP deficiency, we investigated apo B kinetics in CETP-deficient subjects.

CETP-deficient LDL has been shown to be rich in triglyceride and poor in cholesteryl esters $(12,13)$, reflecting the lack of lipid exchange with HDL. We first hypothesized that this abnormal LDL composition may accelerate catabolism and account for the decreased LDL apo B in CETP deficiency. LDL kinetic studies in control subjects were performed to address this hypothesis. To our surprise, CETP-deficient LDL was found to be catabolized more slowly than autologous normal LDL, indicating that the abnormal LDL composition does not result in higher affinity to the LDL receptor. Delayed catabolism of CETP-deficient LDL relative to the normal LDL in this study is consistent with the finding by Hirano et al., who suggested 


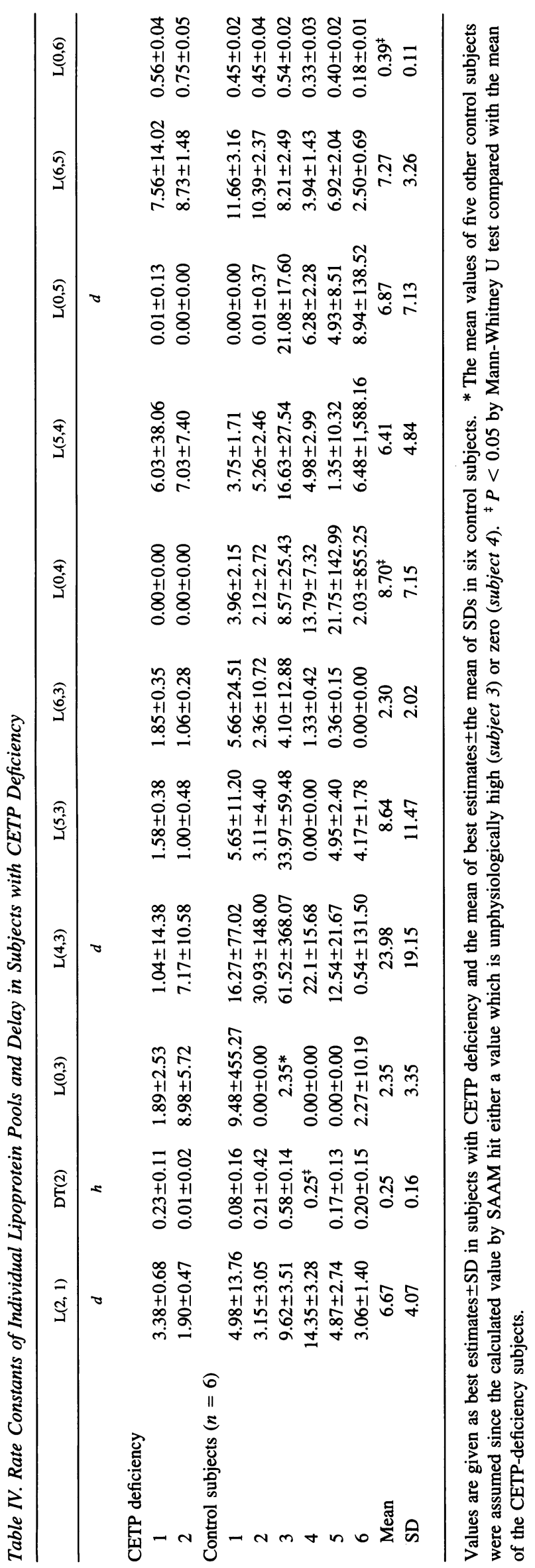

a decreased affinity of CETP-deficient LDL to fibroblast LDL receptors in vitro (31). This result also compares favorably with the finding by Aviram et al. (32) that triglyceride-rich LDL showed less affinity to the LDL receptor. Therefore, we concluded that the altered LDL particles did not have higher affinity to the LDL receptor, and thus could not explain the decreased LDL apo B levels in CETP deficiency.

We then investigated apo B kinetics in two CETP-deficient subjects using endogenous stable isotope labeling. These studies indicate that increased catabolism of LDL apo B is the major mechanism for the decreased LDL apo B levels in CETP deficiency. This result, together with the radiolabeled LDL tracer study, indicates possible up-regulation of LDL receptor activity in CETP deficiency. This conclusion is consistent with the finding in transgenic mice overexpressing human CETP that hepatic LDL receptor mRNA levels were decreased (33). Further, Kushwaha et al. have recently reported that baboons with less CETP activity had higher levels of hepatic LDL receptor mRNA (34). CETP-mediated transfer of cholesteryl esters from HDL to apo B-containing lipoproteins has been postulated to be the major pathway of reverse cholesterol transport in humans (28, 35). In the absence of CETP, it is possible that LDL is less efficient in delivering cholesterol to the liver, resulting in the up-regulation of hepatic LDL receptor activity.

Another finding in the present study was decreased production of VLDL and IDL apo B in the CETP-deficient subjects. There have been recent reports regarding the regulation of hepatic apo B secretion in response to changing intracellular cholesteryl ester concentrations. Tanaka et al. (36) and other groups $(37,38)$ have reported a correlation between hepatic cholesteryl ester concentration and apo B secretion by demonstrating increased apo B secretion induced by the addition of LDL using cultured hepatocytes. Hennessy et al. (39) reported that up-regulation of hepatic apo B mRNA levels was associated with the suppression of LDL receptor mRNA levels in monkeys fed saturated fat and cholesterol. Our results are consistent with the concept that lack of CETP is associated with decreased hepatic apo B secretion and increased hepatic LDL receptor activity, both of which contribute to the decreased steady state concentrations of LDL apo B in CETP deficiency.

The chemical composition of apo B-containing lipoproteins has been shown to be altered in CETP deficiency $(12,40)$, indicating a critical role of CETP for the formation of these lipoproteins. In the present study, direct removal of small VLDL $(\mathrm{L}(0,4))$ and IDL $(\mathrm{L}(0,5))$ were found to be virtually absent in CETP deficiency (Table V), possibly reflecting altered chemical composition. Previous studies suggested that CETP plays a major role in the formation of LDL, based on the marked heterogeneity of LDL size in CETP deficiency $(12,13)$. In the present study, although the overall production rate of LDL apo $B$ was not different from controls, we found that lack of CETP modulated the synthetic pathway for LDL apo B. In normal subjects, LDL was predominantly derived from VLDL via IDL. In contrast, the shunt pathway from VLDL to LDL increased twofold in CETP deficiency, suggesting the possibility that the two discrete synthetic pathways (shunt pathway and cascade pathway through IDL), together with the lack of a subsequent LDL remodeling process, may cause the polydisperse LDL pattern typically observed in homozygous CETP deficiency.

Recently, Foster et al. (41) critically reviewed apo B kinetic studies using stable isotope in which either a linear regression $(42-44)$ or a monoexponenetial function $(45,46)$ was used to 
Table V. Kinetic Parameters of Apo B in Subjects with CETP Deficiency

\begin{tabular}{|c|c|c|c|c|c|c|c|c|c|}
\hline \multirow[b]{2}{*}{ Subjects } & \multicolumn{3}{|c|}{ VLDL } & \multicolumn{3}{|c|}{ IDL } & \multicolumn{3}{|c|}{ LDL } \\
\hline & Concentration & FCR & PR & Conc. & FCR & PR & Concentration & FCR & PR \\
\hline & $m g / d l$ & $d$ & $m g / k g$ per $d$ & $m g / d l$ & $d$ & $\mathrm{mg} / \mathrm{kg}$ per $d$ & $m g / d l$ & $d$ & $\mathrm{mg} / \mathrm{kg}$ per $d$ \\
\hline \multicolumn{10}{|l|}{ CETP deficiency } \\
\hline 1 & 5.6 & $5.4 \pm 0.6$ & 12.2 & 1.7 & $6.0 \pm 21.6$ & 4.2 & 53.2 & $0.56 \pm 0.04$ & 12.0 \\
\hline 2 & 5.4 & $9.0 \pm 1.6$ & 19.3 & 2.2 & $7.0 \pm 2.9$ & 6.3 & 52.3 & $0.75 \pm 0.05$ & 15.7 \\
\hline \multicolumn{10}{|c|}{ Control subjects $(n=6)$} \\
\hline 1 & 7.5 & $8.3 \pm 23.0$ & 24.7 & 5.6 & $7.7 \pm 0.9$ & 17.1 & 109.0 & $0.45 \pm 0.02$ & 19.7 \\
\hline 2 & 4.3 & $7.0 \pm 6.7$ & 12.0 & 3.8 & $7.4 \pm 1.0$ & 11.3 & 108.9 & $0.45 \pm 0.04$ & 19.4 \\
\hline 3 & 5.7 & $29.7 \pm 10.1$ & 67.8 & 4.8 & $25.2 \pm 9.2$ & 48.2 & 94.5 & $0.54 \pm 0.02$ & 20.3 \\
\hline 4 & 12.3 & $10.7 \pm 1.3$ & 52.8 & 4.1 & $18.8 \pm 8.6$ & 30.7 & 84.7 & $0.33 \pm 0.03$ & 11.0 \\
\hline 5 & 4.0 & $11.6 \pm 6.4$ & 18.5 & 3.6 & $23.1 \pm 133.9$ & 32.9 & 101.2 & $0.40 \pm 0.02$ & 16.0 \\
\hline 6 & 12.5 & $6.6 \pm 2.9$ & 32.8 & 8.2 & $8.5 \pm 734.7$ & 27.8 & 95.7 & $0.18 \pm 0.01$ & 6.8 \\
\hline Mean & 7.7 & 12.3 & 34.8 & $5.0^{*}$ & $15.1^{*}$ & $28.0^{*}$ & $99.0^{*}$ & $0.39 *$ & 15.6 \\
\hline SD & 3.5 & 8.0 & 19.6 & 1.6 & 31.7 & 11.8 & 8.6 & 0.11 & 5.0 \\
\hline
\end{tabular}

$* P<0.05$ by Mann-Whitney U test compared with the mean of the CETP deficient subjects. Values for FCRs are given as best estimates \pm SD.

calculate kinetic parameters. None of these methods are considered to be physiologically valid to describe heterogeneous apo B-containing lipoprotein metabolism. Therefore, we developed a multicompartmental model for analysis of our data similar to one previously reported by Barrett et al. (20-22). With this model, the fractional standard deviations for $\mathrm{L}(0,6)$, a fractional catabolic rate for LDL apo B, were $<9 \%$ (Table IV).

Although controversial, it has been proposed that CETP deficiency may be associated with protection against coronary heart disease, based on the observed longevity in one kindred (5) as well as the lack of evidence of coronary heart disease (10) in other kindreds with CETP deficiency. Several other lines of evidence also support this hypothesis. Variation in plasma CETP activities among animal species is positively correlated with the susceptibility to atheroscrelosis (35). CETP mass is directly correlated with the extent of coronary atherosclerosis in monkeys fed a high cholesterol diet (30). Finally, transgenic mice overexpressing simian CETP developed accelerated atherosclerosis (47). The present study, together with our previous metabolic study of apo A-I in CETP deficiency, has established that a lack of CETP has a major influence on the entire spectrum of lipoprotein metabolism. Although the issue as to whether increased apo A-I levels due to delayed catabolism is beneficial still remains to be proven, low LDL levels caused by increased catabolism are likely to be beneficial metabolic alterations.

Table VI. Metabolic Channeling of Apo B in Subjects with CETP Deficiency

\begin{tabular}{|c|c|c|c|c|c|c|c|}
\hline \multirow[b]{2}{*}{ Subjects } & \multicolumn{3}{|c|}{ Removal* from } & \multicolumn{2}{|c|}{ Conversion $^{\ddagger}$ from VLDL to } & \multicolumn{2}{|c|}{ LDL synthesis } \\
\hline & VLDL & IDL & LDL & IDL & LDL & Shunt pathway & Cascade \\
\hline & \multicolumn{7}{|c|}{ percent } \\
\hline \multicolumn{8}{|l|}{ CETP deficiency } \\
\hline 1 & $29.6 \pm 11.9$ & $0.1 \pm 0.7$ & $70.0 \pm 11.7$ & $41.2 \pm 72.8$ & $70.0 \pm 11.7$ & $41.5 \pm 104.3$ & $58.6 \pm 104.3$ \\
\hline 2 & $49.3 \pm 29.4$ & $0.0 \pm 0.0$ & $50.7 \pm 10.9$ & $44.9 \pm 26.8$ & $50.7 \pm 10.9$ & $11.4 \pm 5.3$ & $88.6 \pm 5.3$ \\
\hline \multicolumn{8}{|c|}{ Control subjects $(n=6)$} \\
\hline 1 & $50.7 \pm 144.9$ & $0.0 \pm 0.0$ & $49.3 \pm 147.8$ & $46.2 \pm 135.2$ & $49.3 \pm 147.8$ & $6.3 \pm 2.8$ & $93.7 \pm 0.3$ \\
\hline 2 & $24.4 \pm 69.5$ & $0.1 \pm 2.4$ & $75.6 \pm 70.6$ & $69.2 \pm 62.6$ & $75.6 \pm 70.6$ & $8.6 \pm 11.7$ & $91.4 \pm 11.7$ \\
\hline 3 & $23.2 \pm 56.3$ & $52.4 \pm 51.9$ & $24.4 \pm 8.6$ & $72.8 \pm 55.5$ & $24.4 \pm 8.6$ & $16.4 \pm 15.4$ & $83.6 \pm 15.4$ \\
\hline 4 & $6.9 \pm 0.9$ & $15.4 \pm 7.4$ & $15.3 \pm 7.4$ & $25.1 \pm 7.4$ & $15.3 \pm 7.4$ & $36.9 \pm 14.4$ & $63.1 \pm 14.4$ \\
\hline 5 & $66.2 \pm 37.8$ & $13.2 \pm 28.5$ & $20.6 \pm 11.5$ & $31.8 \pm 34.3$ & $20.6 \pm 11.5$ & $9.7 \pm 16.8$ & $90.3 \pm 16.8$ \\
\hline 6 & $34.4 \pm 8.2$ & $51.3 \pm 815.1$ & $14.4 \pm 8.1$ & $65.6 \pm 823.6$ & $14.4 \pm 8.1$ & $0.0 \pm 0.0$ & $100 \pm 6.2$ \\
\hline Mean & 34.3 & 22.1 & 33.3 & 51.8 & 33.3 & 13.0 & 87.0 \\
\hline SD & 19.4 & 21.9 & 22.2 & 18.6 & 22.2 & 11.8 & 11.8 \\
\hline
\end{tabular}

Values are given as best estimates $\pm S D$. $*(R(0,3)+R(0,4)) / R(3,2)$ represents removal from VLDL, $R(0,5) / R(3,2)$ from IDL, and $R(0,6) / R(3,2)$ from $\operatorname{LDL} .{ }^{\ddagger}(R(5,3)+R(5,4)) / R(3,2)$ represents conversion from VLDL to IDL, and $(R(6,3)+R(6,5)) / R(3,2)$ from VLDL to LDL, which is equal to the removal from LDL since $R(6,3)+R(6,5)=R(0,6)$. $R(I, J)$ is a variable that represents the flux or transport of tracee from compartment $J$ to compartment I. ${ }^{\S}$ Shunt pathway for LDL synthesis represents $R(6,3) / R(0,6)$ and cascade pathway from VLDL through IDL represents $R(6,5) /$ $\mathrm{R}(0,6)$. 
In summary, complete deficiency of CETP results in the increased catabolism of LDL apo B probably by the up-regulation of LDL receptor activity. This study provides new insights into the role of CETP in apo B metabolism and indicates that inhibition of plasma CETP activity may be a novel method of reducing the plasma levels of LDL cholesterol by enhancing LDL catabolism.

\section{Acknowledgments}

We are indebted to Marie Kindt, Glenda Tally, and Yoshiko Doherty for excellent technical support, Bob Butky for quality control of the labeled amino acid, George Grimes and the Pharmaceutical Development Service for pyrogen test of injection materials, and the nursing staffs of the Aoto Hospital, Jikei University School of Medicine, and the National Institutes of Health Clinical Center for nursing care of the study subjects. We are also greatly indebted to the reviewers who gave valuable comments and helped us to rebuild a multicompartmental model.

\section{References}

1. 1988. Report of the National Cholesterol Education Program Expert Pane on detection, evaluation, and treatment of high blood cholesterol in adults. Arch. Intern. Med. 148:36-69.

2. Brown, M. S., and J. L. Goldstein. 1986. A receptor-mediated pathway for cholesterol homeostasis. Science (Wash. DC). 232:34-47.

3. Tall, A. R. 1986. Plasma lipid transfer proteins. J. Lipid Res. 27:361-367.

4. Hesler, C. B., T. L. Swenson, and A. R. Tall. 1987. Purification and characterization of a human plasma cholesteryl ester transfer protein. J. Biol. Chem. 262:2275-2282.

5. Saito, F. 1984. A pedigree of homozygous familial hyperalphalipoproteinemia. Metab. Clin. Exp. 33:629-633.

6. Koizumi, J., H. Mabuchi, A. Yoshimura, I. Michishita, M. Takeda, H. Itoh, Y Sakai, T Sakai, K. Ueda, and R. Takeda. 1985. Deficiency of serum cholesteryl-ester transfer activity in patients with familial hyperalphalipoproteinaemia. Atherosclerosis. 58:175-186.

7. Kurasawa, T., S. Yokoyama, Y. Miyake, and T. Yamamura. 1985. Rate of cholesteryl ester transfer between high and low density lipoproteins in human serum and a case with decreased transfer rate in association with hyperalphalipoproteinemia. J. Biochem. (Tokyo). 98:1499-1508.

8. Brown, M. L., A. Inazu, C. B. Hesler, L. B. Agellon, C. Mann, M. E. Whitlock, Y. L Marcel, R. W. Milne, J. Koizumi, H. Mabuchi, and A. R. Tall. 1989. Molecular basis of lipid transfer protein deficiency in a family with increased high-density lipoproteins. Nature (Lond.). 342:448-451.

9. Shamburek, R. D., M. Nishiwaki, T. Ishikawa, H. Nakamura, K. Ikewaki, L. A. Zech, D. J. Rader, H. B. Brewer, Jr., and C. C. Schwartz. 1993. Cholestery ester transfer protein deficiency: in vivo metabolism of free and esterified cholesterol. Circulation. 88:1-75 (Abstr.).

10. Inazu, A., M. L. Brown, C. B. Hesler, L. B. Agellon, J. Koizumi, K Takata, Y. Maruhama, H. Mabuchi, and A. R. Tall. 1990. Increased high-density lipoprotein levels caused by a common cholesteryl-ester transfer protein gene mutation. N. Engl. J. Med. 323:1234-1238.

11. Yamashita, S., Y. Matsuzawa, M. Okazaki, H. Kako, T. Yasugi, H. Akioka K. Hirano, and S. Tarui. 1988. Small polydisperse low density lipoproteins in familial hyperalphalipoproteinemia with complete deficiency of cholesteryl ester transfer activity. Atherosclerosis. 70:7-12.

12. Bisgaier, C. L., M. V. Siebenkas, M. L. Brown, A. Inazu, J. Koizumi, H Mabuchi, and A. R. Tall. 1991. Familial cholesteryl ester transfer protein deficiency is associated with triglyceride-rich low density lipoproteins containing cholesteryl esters of probable intracellular origin. J. Lipid Res. 32:21-33.

13. Sakai, N., Y. Matsuzawa, K. Hirano, S. Yamashita, S. Nozaki, Y. Ueyama, M. Kubo, and S. Tarui. 1991. Detection of two species of low density lipoprotein particles in cholesteryl ester transfer protein deficiency. Arteriosclerosis. 11:7179 .

14. Ikewaki, K., D. J. Rader, T. Sakamoto, M. Nishiwaki, N. Wakimoto, J. R. Schaefer, T. Ishikawa, T. Fairwell, L. A. Zech, H. Nakamura, et al. 1993. Delayed catabolism of high density lipoprotein apolipoprotein A-I and A-II in human cholesteryl ester transfer protein deficiency. J. Clin. Invest. 92:1650-1658.

15. Havel, R. J., H. A. Eder, and J. H. Bragdon. 1955. The distribution and chemical composition of ultracentrifugally separated lipoproteins in human serum. J. Clin. Invest. 34:1345-1353.

16. Yamashita, S., D. L. Sprecher, N. Sakai, Y. Matsuzawa, S. Tarui, and D. Y. Hui. 1990. Accumulation of apolipoprotein E-rich high density lipoprotein in hyperalphalipoproteinemic human subjects with plasma cholesteryl ester transfer protein deficiency. J. Clin. Invest. 86:688-695.

17. Rader, D. J., W. Cain, L. A. Zech, D. Usher, and H. B. Brewer, Jr. 1993. Variation in lipoprotein (a) concentrations among individuals with the same apolipoprotein (a) isoform is determined by the rate of lipoprotein (a) production. J. Clin. Invest. 91:443-447.

18. Berman, M., and M. Weiss: SAAM Manual. DHEW Publ.No.(NIH). 1978. National Institutes of Health, Bethesda, MD. 85 pp.

19. Cobelli, C., G. Toffolo, and D. M. Foster. 1992. Tracer-to-tracee ratio for analysis of stable isotope tracer data: link with radioactive kinetic formalism. Am. J. Physiol. 262:E968-E975.

20. Parhofer, K. G., P. Hugh, R. Barrett, D. M. Bier, and G. Schonfeld. 1991. Determination of kinetic parameters of apolipoprotein $\mathrm{B}$ metabolism using amino acids labeled with stable isotopes. J. Lipid Res. 32:1311-1323.

21. Parhofer, K. G., P. H. R. Barrett, D. M. Bier, and G. Schonfeld. 1992. Lipoproteins containing the truncated apolipoprotein, Apo B-89, are cleared from human plasma more rapidly than Apo B-100-containing lipoproteins in vivo. $J$. Clin. Invest. 89:1931-1937.

22. Krul, E. S., K. G. Parhofer, P. H. R. Barrett, R. D. Wagner, and G. Schonfeld. 1992. ApoB-75, a truncation of apolipoprotein B associated with familial hypobetalipoproteinemia: genetic and kinetic studies. J. Lipid Res. 33:10371050 .

23. Law, S. W., S. M. Grant, K. Higuchi, A. Hospattankar, K. Lackner, N. Lee, and H. B. Brewer, Jr. 1986. Human liver apolipoprotein B-100 cDNA complete nucleic and derived amino acid sequence. Proc. Natl. Acad. Sci. USA. 83:8142-8146.

24. Knott, T. J., R. J. Pease, L. M. Powell, S. C. Wallis J., S. C. Rall, T. L. Innerarity, B. Blabkhart, W. H. Taylor, Y. Marcel, R. Milne et al. 1986. Complete protein sequence and identification of structural domains of human apolipoprotein B-100. Nature (Lond.). 323:734-738.

25. Yang, C., S.-H. Chen, S. H. Gianturco, W. A. Bradley, J. T. Sparrow, M. Tanimura, W.-H. Li, D. A. Sparrow, H. DeLoof, M. Rossenseu, et al. 1986. Sequence, structure, receptor-binding domains and internal repeats of human apolipoprotein B-100. Nature (Lond.). 323:738-742.

26. Warnick, G. R., M. C. Cheung, and J. J. Albers. 1979. Comparison of current methods for high-density lipoprotein cholesterol quantitation. Clin. Chem. 25:596-604.

27. Bojanovski, M., R. E. Gregg, D. M. Wilson, and H. B. Brewer, Jr. 1987 Semi-automated enzyme-linked immunosorbent assay (ELISA) for the quantification of apolipoprotein B using monoclonal antibodies. Clin. Chim. Acta. 170:27:1-280.

28. Tall, A. R. 1993. Plasma cholesterol ester transfer protein. J. Lipid Res. 34:1255-1274.

29. Marotti, K. R., C. K. Castle, R. W. Murray, E. F. Rehberg, H. G. Polites, and G. W. Melchior. 1992. The role of cholesteryl ester transfer protein in primate apolipoprotein A-I metabolism: Insights from studies with transgenic mice. Arteriosclerosis. 12:736-744.

30. Quinet, E., A. R. Tall, R. Ramakrishnan, and L. Rudel. 1991. Plasma lipid transfer protein as a determinant of the atherogenicity of monkey plasma lipoproteins. J. Clin. Invest. 87:1559-1566.

31. Hirano, K., S. Yamashita, N. Sakai, H. Hiraoka, Y. Ueyama, T. Funahashi, and Y. Matsuzawa. 1992. Low-density lipoproteins in hyperalphalipoproteinemic heavy alcohol drinkers have reduced affinity for the low-density lipoprotein receptor. Clin. Biochem. 25:357-362.

32. Aviram, M., S. Lund-Katz, M. C. Phillips, and A. Chait. 1988. The influence of the triglyceride content of low density lipoprotein on the interaction of apolipoprotein B-100 with cells. J. Biol. Chem. 263:16842-16848.

33. Jiang, X. C., L. Masucci-Magoulas, J. Mar, M. Lin, A. Walsh, J. L. Breslow, and A. R. Tall. 1993. Down-regulation of mRNA for the low density lipoprotein receptor in CETP transgenic mice containing the gene for human cholesteryl ester transfer protein. Mechanism to explain accumulation of lipoprotein B particles. J. Biol. Chem. 268:27406-27412.

34. Kushwaha, R. S., C. A. McMahan, G. E. Mott, K. D. Carey, C. A. Reardon, G. S. Getz, and H. C. McGill Jr. 1991. Influence of dietary lipids on hepatic mRNA levels of proteins regulating plasma lipoproteins in baboons with high and low levels of large high density lipoproteins. J. Lipid Res. 32:1929-1940.

35. Ha, Y. C., and P. J. Barter. 1982. Differences in plasma cholesteryl ester transfer activity in sixteen vertebrate species. Comp. Biochem. Physiol. 71:265269.

36. Tanaka, M., H. Jingami, H. Otani, M. Cho, Y. Ueda, H. Arai, Y. Nagano, T. Doi, M. Yokode, and T. Kita. 1993. Regulation of apolipoprotein B production and secretion in response to the change of intracellular cholesteryl ester contents in rabbit hepatocytes. J. Biol. Chem. 268:12713-12718.

37. Dashi, N. 1992. The effect of low density lipoproteins, cholesterol, and 25-hydroxycholesterol on apolipoprotein B gene expression in HepG2 cells. J. Biol. Chem. 267:7160-7169.

38. Cianflone, K. M., Z. Yasruel, M. A. Rodriguez, D. Y. Vas, and A. D. Snidermann. 1990. Regulation of apoB secretion from HepG2 cells: evidence for a critical role for cholesterol ester synthesis in the response to a fatty acid challenge. J. Lipid Res. 31:2045-2055. 
39. Hennessy, L. K., J. Osada, J. M. Ordovas, R. J. Nocolosi, A. F. Stucchi, M. E. Brousseau, and E. J. Scheafer. 1992. Effect of dietary fats and cholestero on the liver lipid content and hepatic apolipoprotein A-I, B, and E and LDL receptor mRNA levels in cebus monkeys. J. Lipid Res. 33:351-360.

40. Koizumi, J., A. Inazu, K. Yagi, I. Koizumi, Y. Uno, K. Kajanami, S. Miyamoto, P. Moulin, A. R. Tall, H. Mabuchi, and R. Takeda. 1991. Serum lipoprotein lipid concentration and composition in homozygous and heterozygous patients with cholesteryl ester transfer protein deficiency. Atherosclerosis. 90:189-196.

41. Foster, D. M., P. H. R. Barrett, G. Toffolo, W. F. Beltz, and C. Cobelli 1993. Estimating the fractional synthetic rate of plasma apolipoproteins and lipids from stable isotope data. J. Lipid Res. 34:2193-2205.

42. Cryer, D. R., T. Matsushima, J. B. Marsh, M. Yudkoff, P. M. Coates, and J. A. Cortner. 1986. Direct measurement of apolipoprotein B synthesis in human very low density lipoprotein using stable isotopes and mass spectrometry. J. Lipid Res. 27:508-516.

43. Cohn, J. S., D. A. Wagner, S. D. Cohn, J. S. Millar, and E. J. Schaefer. 1990. Measurement of very low density and low density lipoprotein apolipoprotein
(Apo) B-100 and high density lipoprotein Apo A-I production in human subjects using deuterated leucine. Effect of fasting and feeding. J. Clin. Invest. 85:804811.

44. Venkatesan, S., P. Cullen, P. Pacy, D. Holliday, and J. Scott. 1993. Stabe isotopes show a direct relation between VLDL apoB overproduction and serum triglyceride levels and indicate a metabolically and biochemically coherent basis for familial combined hyperlipidemia. Arterioscler. Thromb. 13:1110-1118.

45. Lichtenstein, A. H., D. L. Hachey, J. S. Millar, J. L. Jenner, L. Booth, J. Ordovas, and E. J. Schaefer. 1992. Measurement of human apolipoprotein B-48 and B-100 kinetics in triglyceride-rich lipoproteins using $\left[5,5,5-{ }^{2} \mathrm{H}_{3}\right]$ leucine. $J$. Lipid Res. 33:907-914.

46. Walsh, B. W., I. Schiff, B. Rosner, L. Greenberg, V. Ravnikar, and F. M. Sacks. 1991. Effects of postmenopausal estrogen replacement on the concentrations and metabolism of plasma lipoproteins. N. Engl. J. Med. 325:1196-1204.

47. Marotti, K. R., C. K. Castle, T. P. Boyle, A. H. Lin, R. W. Murray, and G. W. Melchior. 1993. Severe atherosclerosis in transgenic mice expressing simian cholesteryl ester transfer protein. Nature (Lond.). 364:73-75. 